\title{
The multikinase inhibitor midostaurin (PKC4I2A) lacks activity in metastatic melanoma: a phase IIA clinical and biologic study
}

\author{
MJ Millward",', C House', D Bowtell', L Webster', IN Olver², M Gore ${ }^{3}$, M Copeman ${ }^{4}, K_{\text {Lynch }}^{4}$, A Yap ${ }^{5}$, \\ Y Wang ${ }^{5}$, PS Cohen ${ }^{5}$ and J Zalcberg' \\ 'Peter MacCallum Cancer Institute, Melbourne, Victoria, Australia; ${ }^{2}$ Royal Adelaide Hospital, Adelaide, South Australia, Australia; ${ }^{3}$ Royal Marsden \\ Hospital, London, UK; ${ }^{4}$ Novartis Pharmaceuticals Australia Pty Ltd, North Ryde, New South Wales, Australia; ${ }^{5}$ Novartis Pharmaceuticals Inc., East \\ Hanover, NJ, USA
}

\begin{abstract}
Midostaurin (PKC4I2A), N-benzoyl-staurosporine, potently inhibits protein kinase C alpha (PKC $\alpha$ ), VEGFR2, KIT, PDGFR and FLT3 tyrosine kinases. In mice, midostaurin slows growth and delays lung metastasis of melanoma cell lines. We aimed to test midostaurin's safety, efficacy and biologic activity in a Phase IIA clinical trial in patients with metastatic melanoma. Seventeen patients with advanced metastatic melanoma received midostaurin $75 \mathrm{mg}$ p.o. t.i.d., unless toxicity or disease progression supervened. Patient safety was assessed weekly, and tumour response was assessed clinically or by CT. Tumour biopsies and plasma samples obtained at entry and after 4 weeks were analysed for midostaurin concentration, PKC activity and multidrug resistance. No tumour responses were seen. Two (12\%) patients had stable disease for 50 and 85 days, with minor response in one. The median overall survival was 43 days. Seven (41\%) discontinued treatment with potential toxicity, including nausea, vomiting, diarrhoea and/or fatigue. One patient had $>50 \%$ reduction in PKC activity. Tumour biopsies showed two PKC isoforms relatively insensitive to midostaurin, out of three patients tested. No modulation of multidrug resistance was demonstrated. At this dose schedule, midostaurin did not show clinical or biologic activity against metastatic melanoma. This negative trial reinforces the importance of correlating biologic and clinical responses in early clinical trials of targeted therapies.

British Journal of Cancer (2006) 95, 829-834. doi:I0.1038/sj.bjc.660333I www.bjcancer.com
\end{abstract}

Published online 12 September 2006

(c) 2006 Cancer Research UK

Keywords: protein kinase C; melanoma; midostaurin

Midostaurin (PKC412A, CGP41251), N-benzoyl-staurosporine, is a potent inhibitor of calcium- or diacylglycerol-dependent isoforms of protein kinase $\mathrm{C}$ (PKC $\alpha, \mathrm{PKC} \beta \mathrm{I}, \mathrm{PKC} \beta \mathrm{II}$ and $\mathrm{PKC} \gamma)$, and VEGFR2, PDGFR, KIT and Flt-3 kinases (Fabbro et al, 2000; Weisberg et al, 2002). Although midostaurin is a competitive inhibitor of ATP binding to $\operatorname{PKC} \alpha$, midostaurin is most active in inhibiting particulate (active) PKC enzymes from tumour samples (Killion et al, 1995; Ikegami et al, 1996).

In vitro, midostaurin slows tumour cell growth, in G2/M phase, inducing polyploidy, apoptosis and radiosensitivity, with inhibition of the PI3K/Akt pathway (Fabbro et al, 2000; Tenzer et al, 2001). In vivo midostaurin inhibits growth of several murine tumours, potentiates paclitaxel, doxorubicin and radiation, and may affect multidrug resistance (Utz et al, 1994; Fabbro et al, 2000). Angiogenesis is also inhibited by midostaurin (Ozaki et al, 2000).

The incurability of metastatic melanoma indicates a need for new therapy, preferably targeted against molecular changes

\footnotetext{
* Correspondence: Professor MJ Millward, School of Medicine and Pharmacology, Sir Charles Gairdner Hospital Unit M503, Hospital Avenue, Nedlands 6009, Australia; E-mail millward@cyllene.uwa.edu.au Received 28 November 2005; revised 31 July 2006; accepted I August 2006; published online 12 September 2006
}

associated with tumorigenicity (Brown and Kirkwood, 2003). Protein kinase $\mathrm{C}$ alpha activity is elevated in some melanoma cells and is a potential target (Selzer et al, 2002). Midostaurin inhibits PKC $\alpha$ activity in melanoma cells, and delays their lung metastasis in mice (Yoshikawa et al, 2003). So, midostaurin might be useful clinically in patients with metastatic melanoma.

In a Phase I trial, 32 patients with advanced cancer received oral midostaurin at $12.5-300 \mathrm{mg} \mathrm{day}^{-1}$ (Propper et al, 2001). Between two patients with cholangiocarcinoma, one had stable disease and one a partial response for 4 months on midostaurin. No other responses were seen. Frequent but mild toxicities were nausea, vomiting, fatigue and diarrhoea. MTD was not reached, but at 225-300 $\mathrm{mg} \mathrm{day}^{-1}, 15$ out of 16 patients had nausea/vomiting (grade 3 in 3); and six out of 16 had grade 2 diarrhoea. There was minimal myelosuppression.

Midostaurin dose and AUC $(0-24 \mathrm{~h})$ showed linear correlation, but with marked inter-patient variability. Estimated median elimination $t_{1 / 2}$ was 1.6 days (range: 0.9-4.0 days). Several active metabolites, including one (CGP52421 e2) with a median $t_{1 / 2}$ of 36 days, were also detected (Figure 1).

The objectives of this Phase IIa trial of midostaurin in patients with advanced metastatic melanoma were to evaluate midostaurin's effects on measurable disease, to further define its toxicity, and to investigate drug concentrations and biological activity in tumour biopsies and plasma. 
<smiles>CO[C@H]1C(N(C)C(=O)c2ccccc2)C[C@@H]2O[C@]1(C)n1c3ccccc3c3c4c(c5c6ccccc6n2c5c31)C(=O)NC4O</smiles>

CGP 52421 $\mathrm{e} 1, \mathrm{e} 2$

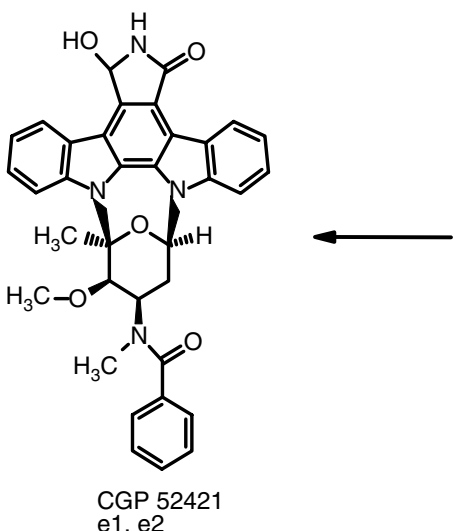<smiles>CO[C@H]1C(N(C)C(=O)c2ccccc2)C[C@@H]2O[C@]1(C)n1c3ccccc3c3c4c(c5c6ccccc6n2c5c31)C(=O)NC4</smiles>

MIDOST<smiles>CO[C@H]1C(N(C)C(=O)c2ccccc2)C[C@@H]2O[C@]1(C)n1c3ccccc3c3c4c(c5c6ccccc6n2c5c31)C(=O)NC4</smiles>

MIDOST

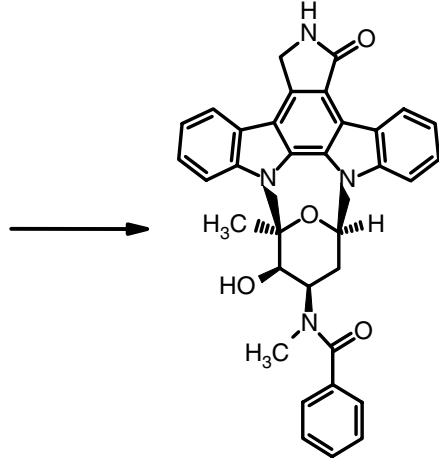

CGP 62221

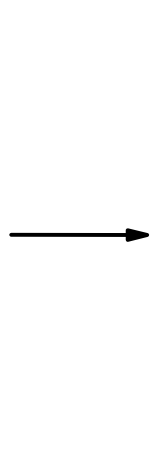<smiles>CN(C(=O)c1ccccc1)[C@H]1C[C@H]2O[C@@](C)([C@@H]1O)n1c3ccccc3c3c4c(c5c6ccccc6n2c5c31)C(=O)NC4</smiles>

Figure I Chemical structures of MIDOSTAURIN and its O-desmethyl metabolite CGP6222I (O-D-MIDOSTAURIN) and 7-hydroxy metabolite CGP5242I (7-OH-MIDOSTAURIN), the later has two epimers, el and e2.

\section{PATIENTS AND METHODS}

\section{Eligibility}

Patients with stage IV metastatic melanoma that had progressed despite any previous therapy were eligible if they were 18 years of age or older, had an ECOG performance status of $0-2$, had adequate haematologic, renal and hepatic function, had bidimensionally measurable disease, and were able to provide informed consent. There was no limit on the amount of prior therapy, but no prior chemotherapy or immunotherapy was permitted in the 4 weeks before study entry. Patients with CNS metastases were eligible. At least the first 14 patients entered were also required to have at least two lesions suitable for excision biopsy (skin, subcutaneous metastases). Written informed consent was obtained from all patients and the protocol was approved by the Human Research Ethics Committees of the participating institutions.

\section{Treatment}

All patients were treated with midostaurin $75 \mathrm{mg}\left(6 \% \mathrm{w} \mathrm{w}^{-1}\right.$ in Gelucire 44 out of 14 ) given orally three times a day $\left(225 \mathrm{mg} \mathrm{day}^{-1}\right)$ continuously until disease progression or unacceptable toxicity. This fixed dose schedule was calculated from the Phase I study, in which higher single daily doses were associated with more GIT toxicity. However, if grade 3 toxicity considered related to midostaurin occurred, treatment was withheld for up to 7 days then continued at $75 \mathrm{mg}$ twice daily $\left(150 \mathrm{mg} \mathrm{day}^{-1}\right)$. Patients were instructed to take midostaurin with food while sitting upright, to reduce nausea.
Patients were reviewed for safety and efficacy of midostaurin weekly for the first month, and then on a monthly basis, or more frequently where symptoms warranted. Disease sites were reevaluated by clinical examination monthly or CT every 2 months, or more frequently if disease progression was suspected.

\section{Assays for biologic activity}

To determine any biologic activity of midostaurin, patients had tumour biopsies and plasma taken for analyses in the week prior to starting midostaurin and again, where practical, on day 28. Tumour biopsies were immediately frozen in liquid nitrogen and stored at $-70^{\circ} \mathrm{C}$ until analysis. Heparinised blood $(10 \mathrm{ml})$ was collected predose and at day 28. Following centrifugation, plasma was stored at $-70^{\circ} \mathrm{C}$ until assay for MDR-reversing ability, and for concentrations of midostaurin and its two main metabolites CGP62221 and CGP52421 e2 (Figure 1).

Preparation of cytosolic and particulate fractions from tumour biopsies Tumours were powdered in liquid nitrogen and homogenised on ice using an Ultra-Turrax in a buffer containing $20 \mathrm{mM}$ HEPES, pH 7.4, $2 \mathrm{~mm}$ EDTA, $25 \mathrm{~mm} \beta$-glycerophosphate, $0.2 \mathrm{~mm}$ DTT, $10 \mu \mathrm{g} \mathrm{ml}^{-1}$ leupeptin, $10 \mu \mathrm{g} \mathrm{ml}^{-1}$ aprotinin, $1 \mu \mathrm{g} \mathrm{ml}^{-1}$ pepstatin, $1 \mu \mathrm{M}$ sodium orthovanadate and $0.5 \mathrm{~mm}$ PMSF. Extracts were then sonicated in an ice cold sonicating bath for $5 \mathrm{~min}$ before centrifugation at $1000 \mathrm{~g}$ for $5 \mathrm{~min}$ to remove cellular debris. Supernatants were centrifuged at $50000 \mathrm{~g}$ for $15 \mathrm{~min}$ to separate cytosolic (supernatant) and particulate (pellet) fractions. The supernatant was kept as 'cytosolic' fraction. The pellet was further extracted by resuspension in the original lysis buffer including $1 \%$ 
NP-40. Following sonication for $5 \mathrm{~min}$ on ice, the extract was centrifuged at $50000 \mathrm{~g}$ for $15 \mathrm{~min}$. The supernatant from this spin (which derived from the original pellet) was kept as the 'particulate' fraction. All steps were performed at $4{ }^{\circ} \mathrm{C}$ or on ice.

Protein measurement The protein concentrations of the cytosolic and particulate fractions were measured after TCA precipitation using the Dc protein assay kit (Bio-Rad).

$P K C$ activity measurements Intratumoral total PKC activity was measured in cytosolic and particulate fractions using protamine sulphate as the substrate, following the method of a validated assay (Budworth and Gescher, 1995). The PKC assay was performed with $4-5 \mu \mathrm{l}$ of the cytosol or particulate extract $(2-50 \mu \mathrm{g}$ protein) in a total reaction volume of $200 \mu \mathrm{l}$, including $200 \mu \mathrm{g} \mathrm{ml}^{-1}$ protamine sulphate, $150 \mu \mathrm{M} \quad\left(\gamma-{ }^{32} \mathrm{P}\right)$ ATP $\left(200\right.$ c.p.m. pmol $\left.{ }^{-1}\right)$ in a buffer containing $20 \mathrm{~mm}$ Tris- $\mathrm{HCl}, \mathrm{pH} 7.4,10 \mathrm{~mm}$ magnesium acetate and $0.5 \mathrm{~mm}$ EGTA. The reaction was terminated after 6-7 min $\left(30^{\circ} \mathrm{C}\right)$ by spotting $35 \mu \mathrm{l}$ of the mix onto P81 phosphocellulose paper, followed by washing in $75 \mathrm{~mm}$ phosphoric acid. Bound, phosphorylated protamine sulphate was quantitated by scintillation counting of the phosphocellulose papers. Protein kinase $C$ activity was determined by phosphate incorporation into protamine sulphate and expressed as picomolar of phosphate transferred min $\mathrm{mg}^{-1}$ protein. Measurements were performed in triplicate. Each patient's pretreatment and day 28 biopsies were processed together and analysed in the same assay run. Up to six patients' samples could be analysed in one day to minimise interassay variability. Initial experiments on melanoma biopsies from nontrial patients showed addition of $10 \mu \mathrm{m}$ midostaurin to melanoma biopsies inhibited phosphorylation.

Western blotting for PKC isoform abundance For three patients, $2 \mu \mathrm{g}$ of cytosol and particulate proteins from baseline and day 28 biopsies were resolved on $15 \%$ acrylamide SDS-PAGE gels, transferred onto PVDF membrane and probed with antibodies to PKC isoforms (Santa Cruz).

Drug concentrations in plasma and tumour tissue Plasma concentrations of midostaurin and its two main metabolites CGP 62221 and CGP52421 e2 were determined using an HPLC method with fluorescence detection as reported previously (Van Gijn et al, 1995; Propper et al, 2001). Homogenisation of the tumour tissue by freeze-fractionating proved impossible. Therefore, the tumour tissue was frozen and cut into as small as possible pieces with a scalpel. The pieces were weighed, added to $1 \mathrm{ml}$ of water, vortexed and thereafter treated like plasma. The assay for plasma samples was validated with acceptable calibration curves, within-study variability and total recovery. The limit of quantitation (LOQ) in these analyses (defined as the concentration of the lowest QC sample with a mean recovery of $80-120 \%$ and a CV $\leqslant 20 \%$ ) was $36 \mathrm{nmoll}^{-1}$ for MIDOSTAURIN, $61 \mathrm{nmoll}^{-1}$ for CGP 62221, and $265 \mathrm{nmoll}^{-1}$ for CGP52421 e2. Due to limited availability of tumour tissue, the within-study validation for tumour assay was not performed. The tissue assay showed good recovery for PKC412, 95.8 $\pm 6.2 \%$, and for CGP62221, 103.2 $\pm 13.0 \%$. The LOQ in tissue homogenate was $48 \mathrm{nmoll}^{-1}$ for midostaurin, $82 \mathrm{nmoll}^{-1}$ for CGP 62221, and $357 \mathrm{nmoll}^{-1}$ for CGP52421 e2.

Potential modulation of multidrug resistance This was determined using a previously reported method that assessed the capacity of cremophor EL to inhibit MDR ${ }^{10}$. Briefly, the ability of the patient's plasma to modulate ex vivo intracellular daunorubicin accumulation in multidrug resistant cells (R100; CCRF CEM cells resistant to $100 \mathrm{ng} \mathrm{ml}^{-1}$ vinblastine) was measured using fluorescence detection. The activity of $20 \mu \mathrm{g} \mathrm{ml}^{-1}$ Valspodar (PSC833, an inhibitor of P-glycoprotein) added to the patient's prestudy plasma sample defined $100 \%$ reversal (no accumulation of daunorubicin). In addition, $20 \mu \mathrm{g} \mathrm{ml}^{-1}$ midostaurin was added to a prestudy sample for estimation of potential activity, and as an inter-patient control. The modulating ability of day 29 plasma samples was determined relative to this. All assays were performed in triplicate. Blank plasma was spiked with $1.0 \mu \mathrm{l} \mathrm{ml}^{-1}$ cremophor EL and run as an inter-assay control. This concentration of cremophor EL caused approximately $50 \%$ inhibition of maximum daunorubicin accumulation (Webster et al, 1993). The accuracy of the control was always $>75 \%$.

\section{Sample size}

It was planned to recruit 14 patients with disease suitable for biopsy as the first cohort. If no responses were seen, the trial would close. If at least one response occurred, a further 13 patients (not necessarily with disease suited for biopsy) would be recruited. Response and toxicity were assessed using WHO criteria.

\section{RESULTS}

\section{Patient demographics and prior therapies}

Seventeen patients with progressive metastatic melanoma were enrolled in the study (Table 1). All were Caucasian, aged 26-77

Table I Patient demographics and tumour responses

\begin{tabular}{|c|c|c|c|c|}
\hline Patient & Age/sex & Prior therapy & Days on midostaurin & Best response (duration) \\
\hline I & $52 M$ & Chemotherapy & 60 & PD \\
\hline 2 & $5 \mid M$ & Chemotherapy, tamoxifen & 15 & PD \\
\hline 3 & $34 M$ & Chemotherapy & 58 & PD \\
\hline 4 & $45 \mathrm{~F}$ & Chemotherapy & 16 & PD \\
\hline 5 & $57 \mathrm{~F}$ & Chemotherapy, tamoxifen, radiation therapy & 57 & SD (50 days) \\
\hline 6 & $60 \mathrm{~F}$ & Chemotherapy, radiation therapy & 8 & PD \\
\hline 7 & $52 M$ & Radiation therapy & 23 & PD \\
\hline 8 & $68 M$ & Chemotherapy, radiation therapy & 33 & PD \\
\hline 9 & $54 M$ & Chemotherapy, tamoxifen, radiation therapy & 37 & PD \\
\hline 10 & $53 M$ & Radiation therapy & 64 & PD \\
\hline | | & $63 M$ & Chemotherapy & 56 & PD \\
\hline 12 & $74 M$ & None & 113 & SD (85 days) \\
\hline 13 & $55 M$ & Chemotherapy, tamoxifen & 25 & NA \\
\hline 14 & $59 M$ & Chemotherapy & 57 & PD \\
\hline 15 & $77 F$ & Tamoxifen & 27 & PD \\
\hline 16 & $26 M$ & Chemotherapy & 15 & PD \\
\hline 17 & $56 \mathrm{~F}$ & Tamoxifen, radiation therapy & 57 & PD \\
\hline
\end{tabular}

$\mathrm{PD}$, progressive disease; SD, stable disease ( $<25 \%$ increase overall diameter of any lesion; no new lesions, after at least 4 weeks); NA, not assessable. 
(median: 55) years, with 12 males and 5 females. Patients' median ECOG performance status was 1 at study entry. Twelve had received chemotherapy (most commonly with dacarbazine, cisplatin or carmustine). Six had received immunotherapy: five with $\alpha$-interferon and four with interleukin 2. Seven had also received radiation therapy and six had received tamoxifen.

\section{Efficacy and safety}

No patient obtained a tumour response on midostaurin therapy. Two out of $17(12 \%)$ had stable disease for 50 and 85 days respectively until tumour progression. In one patient (number 12 in Table 1) - the only patient who had not been pretreated for metastatic melanoma - a brief minor tumour response was seen. Fourteen out of $17(82 \%)$ had progressive disease, and one patient was not assessable for response. All patients have died. The median survival was 43 days (range: 8 -113 days).

No patient's ECOG performance status improved while on study. Eight $(47 \%)$ had no change, and nine $(53 \%)$ patients had worsening of their performance status.

Ten patients discontinued the study due to unsatisfactory therapeutic effect and 7 (41\%) patients discontinued from the study owing to nausea, vomiting, diarrhoea and/or fatigue, possibly related to the study drug, in association with lack of therapeutic response. two out of 17 patients died on study, although their deaths were not thought to be related to midostaurin therapy. Two patients required dose modification of midostaurin for nausea or vomiting.

Elevated liver enzymes (alanine transaminase or aspartate transaminase) possibly linked to therapy were recorded in four patients but only one reached grade 2 severity. Four patients had hyperglycemia, one of Grade 2 severity. Anaemia occurred in 12 patients, in five of whom it reached grade 2 .

\section{Biologic activity of midostaurin}

All 17 patients had baseline tumour biopsies and plasma samples taken for biologic assays at baseline. Nine patients had repeat biopsies and 12 repeat plasma samples, with the remaining patients discontinuing the study early.

Results of PKC assay on tumour biopsies are shown in Figure 2. Compared to the pretreatment biopsy, cytosolic PKC activity was reduced by $7-91 \%$ in seven out of nine patients. Particulate PKC activity was reduced by $11 \%$ to $79 \%$ in four out of nine patients. Only one patient (Patient 10 ) had $>50 \%$ inhibition in both fractions; however, this patient had progressive disease. On day 0 , the percentage of the total PKC activity present in the particulate fraction ranged from 12 to $37 \%$ and on day 28 it ranged from 11 to $35 \%$. The percentage of the total PKC activity present in the

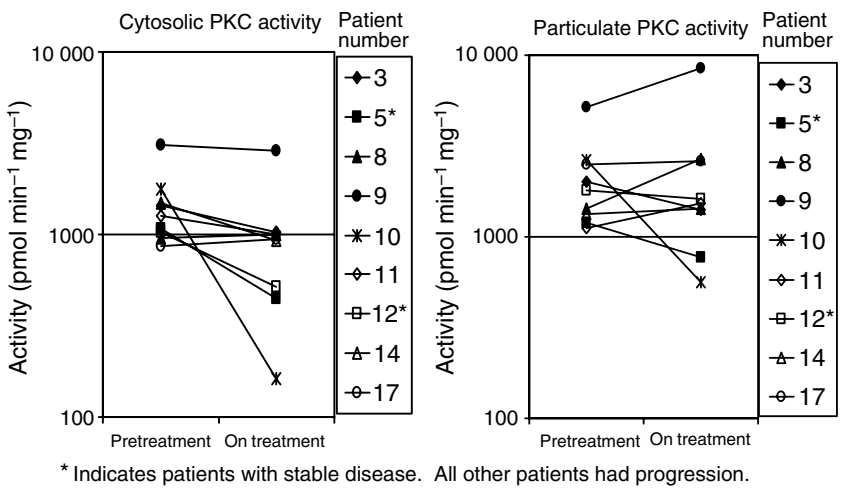

Figure 2 PKC activity in patients' melanoma biopsies before and during midostaurin therapy.
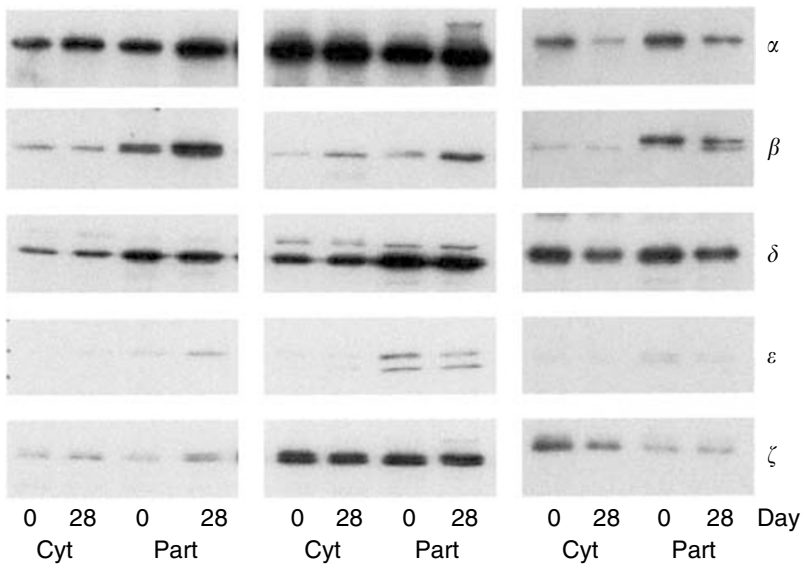

$956 \quad 972 \quad 1432 \quad 3002$

3093287851718482

$1034517 \quad 18041605$ PKC Act.

Figure 3 Western blots of PKC isoforms in melanoma biopsies from three patients before and during midostaurin therapy (left to right, patient number $8,9,12) . \quad$ Cyt $=$ cytosolic, Part $=$ particulate, $P K C$ Act $=$ PKC activity on corresponding day.

particulate fraction fell from day 0 to day 28 in two out of nine patients - in patient 10 from 19.1 to $15.4 \%$ and in patient 11 from 15.7 to $11.1 \%$.

Varying patterns of PKC isoforms were seen in three patients (Figure 3) Protein kinase $\mathrm{C}$ alpha was predominant in two patients. However, one of these patients, who was resistant to midostaurin (unchanged cytosolic activity and 65\% increase in particulate activity), showed an abundance of $\mathrm{PKC} \xi$, an isoform refractory to inhibition by midostaurin $\left(\mathrm{IC}_{50}>1000 \mu \mathrm{M}\right)$. The third patient (patient 12) had predominance of $\mathrm{PKC} \delta$, which is only moderately sensitive to midostaurin $\left(\mathrm{IC}_{50} 0.36 \mu \mathrm{M}\right)$. This patient had stable disease for 85 days.

\section{Modulation of multidrug resistance and tissue/plasma distribution}

Addition of $20 \mu \mathrm{g} \mathrm{ml}^{-1}$ midostaurin to pretreatment plasma produced $14-64 \%$ (mean $40 \%$ ) of potential maximal reversal of multidrug resistance. However, plasma from patients receiving midostaurin showed $<20 \%$ potential maximum reversal in all 12 patients, and in 10 out of 12 patients it was $<10 \%$.

\section{Plasma and tumour concentrations of midostaurin and metabolites}

Concentrations of midostaurin and its two metabolites CGP62221 and CGP52421 e2 in plasma and tumour after approximately 1 month $75 \mathrm{mg}$ tid doses are shown in Table 2. In plasma, midostaurin trough concentrations ranged between 771 to $4649 \mathrm{~nm}$ (median $2342 \mathrm{~nm}$ ), and it was $\sim 2$-fold lower than CGP62221 (median 5433 nM) and $\sim 7$-fold lower than CGP52421 $(18429 \mathrm{nM})$. In tumour tissue, the concentration differences between midostaurin and its metabolites were less pronounced. Midostaurin tissue concentration $593 \mathrm{~nm}$ (median) was comparable to CGP62221 (710 nM), and only 2-fold lower than CGP52421 $(1516 \mathrm{nM})$. The tissue to plasma concentration ratio was similarly low between midostaurin and CGP62221, 0.29 and 0.20, respectively, and the ratio for CGP52421 was the lowest, 0.083 .

\section{DISCUSSION}

In this phase IIA clinical trial, no activity of midostaurin at the $75 \mathrm{mg}$ tid dosing regimen was observed, and toxicity led to early 
Table 2 Plasma and tissue concentrations of midostaurin and its metabolites CGP6222I and CGP5242I e2 epimer

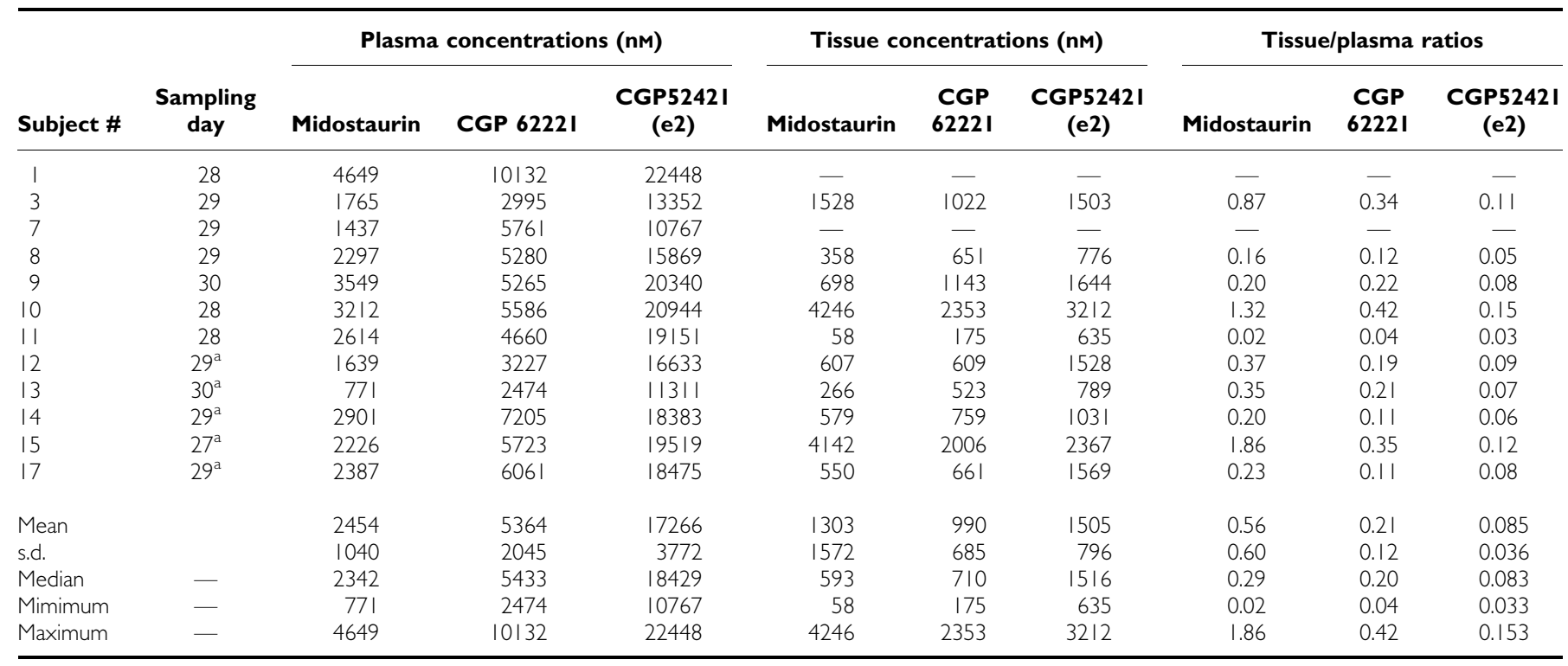

${ }^{2}$ Represent blood sampling times only; tumour tissue samples were collected at 2-7 days before or after blood samples.

discontinuation in seven out of $17(41 \%)$ patients with metastatic melanoma. Most patients had received prior chemotherapy, had large metastases amenable to biopsy, and had short life expectancy. However, these results are similar to the negative results of Phase II trial in melanoma with ISIS3521 (an antisense oligonucleotide against $\mathrm{PKC} \alpha$ ) in which no responses were seen in 23 chemo-naïve patients (Fumoleau et al, 2000).

Grade 3 toxicity was infrequent, but a constellation of less severe symptoms including nausea, vomiting, diarrhoea and fatigue, contributed to the decision to discontinue midostaurin in seven out of $17(41 \%)$ patients. After the start of this trial, the final report of a Phase I study (Propper et al, 2001) suggested $75 \mathrm{mg}$ bid $\left(150 \mathrm{mg} \mathrm{day}^{-1}\right)$ as more tolerable midostaurin dosing for longterm administration. However, a recent Phase II trial of midostaurin to inhibit activated Flt3 kinase in acute myeloid leukaemia (AML) found $225 \mathrm{mg} \mathrm{day}^{-1}$ well-tolerated and had promising activity (Stone et al, 2005).

A major component of this trial was procurement of tumour and plasma samples for evaluation of target inhibition and pharmacodynamic efficacy. Because many patients had disease progression and deteriorating performance status at the first assessment, only nine of the 17 patients were able to have a repeat biopsy performed after 4 weeks of midostaurin treatment. The results of the assay for inhibition of PKC activity were interesting. Despite midostaurin's potency as an inhibitor of the major isoforms of PKC (IC50 $22 \mathrm{nM}$ for PKC $\alpha$ ) (Fabbro et al, 2000), it has been a challenge to increase free concentration to an optimal level because of its high plasma protein binding (99\%, Novartis internal report). For a plasma concentration of $2342 \mathrm{~nm}$ (median), the free concentration will be only $23.4 \mathrm{~nm}$, which is in the same range as the $\mathrm{IC}_{50}$ against PKC $\alpha$. Although the two metabolites CGP62221 and CGP52421 are also active against PKC isotypes, their in vivo activity is probably limited. CGP62221 has a weaker activity (IC50 $120 \mathrm{nM}$ ) than that of the parent drug. CGP52421 has a similar activity (IC50 $50 \mathrm{nM}$ ) as the parent drug and a higher plasma concentration, but its substantially high plasma protein binding ( $\gg 99 \%$, Novartis internal report) renders it less active in vivo than the parent drug. Thus, considering the large inter-patient variability for midostaurin plasma concentration and the marginal free concentration relative to the $\mathrm{IC}_{50}$ value, it was not surprising that the results showed an inconsistent and variable inhibition of PKC activity in melanoma deposits in vivo.

In a small sample of three patients' tumours, two out of three expressed PKC isoforms known to be insensitive to inhibition by midostaurin. However, larger studies on PKC isoforms in human tumours are needed to determine the significance of this finding. Solid tumours such as melanoma may also be poorly perfused and hypoxic, so that low penetration of midostaurin (tissue/plasma ratio median 0.29) into solid tumours may also account for inconsistent intra-tumoral PKC inhibition.

Our results are in contrast to those obtained with midostaurin in AML where inhibition of autophosphorylation of mutated Flt-3 was documented in leukaemic blasts isolated from patients receiving midostaurin (Stone et al, 2005). In 70\% of AML patients, there was a $50 \%$ reduction of peripheral blood blast cells, and in $25 \%$ of patients a $50 \%$ reduction in bone marrow blast cells.

Because midostaurin had been reported to modulate multidrug resistance, we determined this potential in patients' plasma. The results showed negligible effect, indicating midostaurin is unlikely to have therapeutic potential as a clinical modulator of such resistance at the dose of $225 \mathrm{mg}$ per day.

Our results show no clinical activity of midostaurin in metastatic melanoma. This schedule did not show pharmacodynamic efficacy against target PKC isoforms. Other trials with midostaurin as a single agent have, however, demonstrated biologic and clinical activity at the same schedule when the patient population was preselected for expression of midostaurin targets, such as mutated FLT3 kinase, in AML patients. Demonstrating efficacy and target modulation in future midostaurin trials may depend on preselecting patients with constitutively activated (phosphorylated) midostaurin targets: PKC isotypes $\alpha, \beta$ and $\gamma$, FLT3, c-kit, KDR, and PDGF receptor $\alpha$ and $\beta$.

\section{ACKNOWLEDGEMENTS}

We are grateful to the patients and their families who participated, and to the clinical and laboratory staff who carried out the studies involved. This study was sponsored by Novartis AG, manufacturer of midostaurin. 


\section{REFERENCES}

Brown CK, Kirkwood JM (2003) Medical management of melanoma. Surg Clin N Am 83: 283-322

Budworth J, Gescher A (1995) Differential inhibition of cytosolic and membrane-derived protein kinase $\mathrm{C}$ activity by staurosporine and other kinase inhibitors. FEBS Lett 362(2): 139-142

Fabbro D, Ruetz S, Bodis S, Pruschy M, Csermak K, Man A, Campochiaro P, Wood J, O'Reilly T, Meyer T (2000) PKC412 - a protein kinase inhibitor with a broad therapeutic potential. Anticancer Drug Res 15: $17-28$

Fumoleau P, Gore M, Roelevink M, de Vries M, Smyth J, Aamdal S, Vermoken J, Ravaud A (2000) Phase II trial with antisense oligonucleotide ISIS3521/CGP64128A in melanoma patients: a report from the EORTC/ECSG. Ann Oncol 11(Suppl 4): 128 (abstr)

Ikegami Y, Yano S, Nakao K (1996) Antitumor effect of CGP41251, a new selective protein kinase $\mathrm{C}$ inihibitor, on human non-small cell lung cancer cells. Jpn J Pharmacol 70(1): 65-72

Killion JJ, Beltran P, O'Brian CA, Yoon SS, Fan D, Wilson MR, Fidler IJ (1995) The antitumor activity of doxorubicin against drug-resistant murine carcinoma is enhanced by oral administration of a synthetic staurosporine analogue, CGP41251. Oncol Res 7(9): 453-459

Ozaki H, Seo MS, Ozaki K, Yamada H, Yamada E, Okamoto N, Hofmann F, Wood JM, Campochiaro P (2000) Blockade of vascular endothelial cell growth factor receptor signalling is sufficient to completely prevent retinal neovascularization. Am J Pathol 56: 697-707

Propper DJ, McDonald AC, Man A, Thavasu P, Balkwill F, Braybrooke JP, Caponigro F, Graf P, Dutreix C, Blackie R, Kaye SB, Ganesan TS, Talbot DC, Harris AL, Twelves C (2001) Phase I and pharmacokinetic study of PKC412, an inhibitor of protein kinase C. J Clin Oncol 19: 1485-1492

Selzer E, Okamoto I, Lucas T, Kodym R, Pehamberger H, Jansen B (2002) Protein kinase $\mathrm{C}$ isoforms in normal and transformed cells of the melanocytic lineage. Melanoma Res 12: $201-209$
Stone RM, De Angelo DJ, Klimek V, Galinksy I, Estey E, Nimer SD, Grandin W, Lebwohl D, Wang Y, Cohen P, Fox EA, Neuberg D, Clark J, Gilliland DG, Griffin JD (2005) Acute myeloid leukemia patients with an activating mutation in FLT3 respond to a small molecule FLT3 tyrosine kinase inhibitor, PKC412. Blood 105(1): 54-60. (Epub 2004 Sep 2)

Tenzer A, Zingg D, Rocha S, Hemmings B, Fabbro D, Glanzmann C, Shubiger PA, Bodis S, Pruschy M (2001) The phosphatidylinositide $3^{\prime}$-kinase/Akt survival pathway is a target for the anticancer and radiosensitizing agent PKC412, an inhibitor of protein kinase C. Cancer Res 1: $3-10$

Utz I, Hofer S, Regenass U (1994) The protein kinase C inhibitor CGP41251, a staurosporine derivative with antitumour activity, reverses multidrug resistance. Int J Cancer 57: 4-110

Van Gijn R, Van Tellingen O, de Clippeleir JJM, Hillebrand MJ, Boven E, Vermorken JB, ten Bokkel Huinink WW, Schwertz S, Graf P, Beijnen JH (1995) Analytical procedure for the determination of the new antitumour drug $N$-benzoylstaurosporine and three potential metabolites in human plasma by reversed-phase high-performance liquid chromatography. J Chromatogr B Biomed Appl 667: 269-276

Webster L, Linsenmeyer M, Millward M, Morton C, Bishop J, Woodcock D (1993) Measurement of Cremophor EL following taxol: plasma levels sufficient to reverse drug exclusion mediated by the multidrug resistance phenotype. J Natl Cancer Inst 85: 1685-1690

Weisberg E, Boulton C, Kelly LM, Manley P, Fabbro D, Meyer T, Gilliland DG, Griffin JD (2002) Inhibition of mutant FLT3 receptors in leukemia cells by the small molecule tyrosine kinase inhibitor PKC412. Cancer Cell 1: $3-43$

Yoshikawa N, Nakamura K, Yamaguchi Y, Kagota S, Shinozuka K, Kunitomo M (2003) Effect of PKC412, a selective inhibitor of protein kinase C, on lung metastasis in mice injected with B16 melanoma cells. Life Sci 72: $1377-1387$ 